\title{
Cellular Bases of Neocortical Activation: Modulation of Neural Oscillations by the Nucleus Basalis and Endogenous Acetylcholine
}

\author{
Raju Metherate, Charles L. Cox, and John H. Ashe \\ Departments of Neuroscience and Psychology, University of California, Riverside, California 92521
}

In the mammalian neocortex, the EEG reflects the state of behavioral arousal. The EEG undergoes a transformation, known as activation, during the transition from sleep to waking. Abundant evidence indicates the involvement of the neurotransmitter acetylcholine (ACh) in EEG activation; however, the cellular basis of this involvement remains unclear. We have used electrophysiological techniques with in vivo and in vitro preparations to demonstrate actions of endogenous ACh on neurons in auditory neocortex. In vivo stimulation of the nucleus basalis (NB), a primary source of neocortical ACh, (1) elicited EEG activation via cortical muscarinic receptors, (2) depolarized cortical neurons, and (3) produced a change in subthreshold membrane potential fluctuations from large-amplitude, slow (1-5 Hz) oscillations to low-amplitude, fast $(20-40 \mathrm{~Hz})$ oscillations. The NB-mediated change in pattern of membrane potential fluctuations resulted in a shift of spike discharge pattern from phasic to tonic. Stimulation of afferents in the in vitro neocortex elicited cholinergic actions on putative layer 5 pyramidal neurons. Acting via muscarinic receptors, endogenous ACh (1) reduced slow, rhythmic burst discharge and facilitated higher-frequency, single-spike discharge in burst-generating neurons, and (2) facilitated the appearance and magnitude of intrinsic membrane potential oscillations. These in vivo and in vitro observations suggest that neocortical activation results from muscarinic modulation of intrinsic neural oscillations and firing modes. Rhythmic-bursting pyramidal neurons in layer 5 may act as cortical pacemakers; if so, then modifying their discharge characteristics could alter local cortical networks. Larger, intercortical networks could also be modified, due to the widespread projections of NB neurons. Thus, NB cholinergic neurons may play a critical role in producing different states of neocortical functlon.

Early electrophysiological recordings of neocortical activity revealed the EEG activation (desynchronization) that signifies behavioral arousal (Jasper and Carmichael, 1935). Since then, attempts to identify brain mechanisms of arousal have focused on brainstem neurons and the cholinergic system, since either behavioral arousal or stimulation of the midbrain reticular formation results in cortical release of $\mathrm{ACh}$ and $\mathrm{EEG}$ activation

Received Mar. 10, 1992; revised May 14, 1992; accepted June 18, 1992.

We thank Ms. C. Killian for technical assistance. This work was supported by the National Science Foundation (BNS 9008818, IBN 9118872).

Correspondence should be addressed to John H. Ashe, Ph.D., Departments of Neuroscience and Psychology - 075, University of California, Riverside, CA 92521.

Copyright (c) 1992 Society for Neuroscience $0270-6474 / 92 / 124701-11 \$ 05.00 / 0$
(Moruzzi and Magoun, 1949; Kanai and Szerb, 1965; Jasper and Tessier, 1971). Recent studies have identified the nucleus basalis (NB) of Meynert of the basal forebrain as the primary source of cortical ACh (Johnston et al., 1981; Rye et al., 1984). Given that brainstem cholinergic neurons do not, in general, project to neocortex, but that ascending projections from the reticular formation do terminate in the NB region (Wainer and Mesulam, 1990), the NB may form an important link in AChmediated cortical activation (Shute and Lewis, 1967; Detari and Vanderwolf, 1987; Steriade and Buzsaki, 1990).

Several lines of evidence indicate a relationship between NB activity, ACh, and arousal. The discharge rates of NB neurons vary with the degree of EEG activation, greater NB activity being associated with an activated cortex (Detari and Vanderwolf, 1987; Buzsaki et al., 1988). Also, excitotoxic NB lesions or systemic administration of muscarinic cholinergic receptor antagonists renders the cortical EEG resistant to desynchronization in awake animals (Stewart et al., 1984; Buzsaki et al., 1988). Finally, stimulation of the NB results in cortical ACh release and EEG activation (Belardetti et al., 1977; Casamenti et al., 1986; Metherate and Ashe, 1991). These findings indicate a role for NB cholinergic neurons in cortical activation.

NB cholinergic activity is also implicated in higher cognitive functions. In humans, Alzheimer's disease is associated with degeneration of NB neurons and corresponding losses of cortical cholinergic markers, which parallel the degrec of cognitive dysfunction (Davies and Maloney, 1976; Perry et al., 1978; Whitehouse et al., 1982; Sims et al., 1983). Similarly, NB and cortical $\mathrm{ACh}$ deficits in experimental animals impair performance in specific behavioral tasks (Hagan and Morris, 1988). Electrophysiological studies indicate that the discharge rates of NB neurons increase transiently during the acquisition of learned behaviors (Rigdon and Pirch, 1986; Richardson and DeLong, 1990) and are closely tied to the expectation of reward (Richardson and DeLong, 1990; Wilson and Rolls, 1990).

While much correlative evidence points to a critical role for NB cholinergic neurons in arousal and cognition, the cellular bases of such actions at the cortex are unclear. As an initial step in understanding these processes, we have used in vivo and in vitro preparations of neocortex to determine the cellular consequences of cholinergic involvement in neocortical activation.

\section{Materials and Methods}

In vivo experiments. Male Sprague-Dawley rats (250-350 gm) were anesthetized with urethane (ethyl carbamate, $1.5 \mathrm{gm} / \mathrm{kg}$, i.p.), supplemented as needed $(0.2 \mathrm{gm} / \mathrm{kg}$ ) so that noxious stimulation (e.g., tail pinch) did not elicit either reflex movement or changes in EEG activity. A catheter inserted into the external jugular vein allowed for subsequent drug administration. The rat was placed in a stereotaxic apparatus, on 
a heating pad maintained at $37^{\circ} \mathrm{C} . \Lambda$ glass microelectrode $(3 \mathrm{M} \mathrm{NaCl})$ inserted into auditory cortex was used to record extracellular activity (bandpass DC-10 kHz), which was filtered off line for preparation of illustrations (bandpass for EEG, 1-100 Hz; unit activity, $0.1-10 \mathrm{kHz}$, positive polarity upward). Analysis of the frequency distribution of power (power spectrum analysis) in the EEG over the $1-50 \mathrm{~Hz}$ range was performed, using computer software (AXOGRAPH, Axon Instruments), by digitally sampling the signal off line at $200 \mathrm{~Hz}$. For simultaneous extracellular and intracellular recordings, an insulated stainless steel electrode (50 $\mu \mathrm{m}$ diameter) was used to record the EEG at a 1.0 $\mathrm{mm}$ depth, while a microelectrode $\left(4 \mathrm{M} \mathrm{K}^{+}\right.$-acetate, $\left.40-80 \mathrm{M} \Omega\right)$ was used for intracellular recordings, with current injection by way of an active bridge circuit. Following placement of electrodes, the cortex was covered with warmed agar ( $4 \%$ in saline). Additional procedures to minimize pulsations for intracellular recordings included tracheal cannulation and lumbar suspension.

Bipolar NB stimulation (tip separation, about $0.5 \mathrm{~mm}$, generally in the mediolateral plane) consisted of 0.1 -msec-duration stimulus pulses, in trains of $20-100$ pulses, $100-200 / \mathrm{sec}, 100-500 \mu \mathrm{A}$. After the optimally effective NB stimulation sites had been determined (see Results), the stereotaxic coordinates that were routinely used for placement of the stimulating electrodes were (in mm, relative to bregma) AP -1.4 , ML 2.0, and 6.4 below the pial surface (coordinates for the medial electrode; cf. Paxinos and Watson, 1986). For chemical stimulation, glutamate (30-180 $\mathrm{nmol}$ in saline) was infused using a syringe pump over $15 \mathrm{sec}$ to $5 \mathrm{~min}$ via a 30 gauge cannula attached to the stimulating electrodes. Cortical administration of atropine sulfate was by iontophoresis (20-60 nA; multibarrel iontophoresis micropipette glued to the recording electrode) or direct application to the cortical surface (50-320 $\mu \mathrm{M}$ in saturated cotton gauze). Experiments were terminated by barbiturate overdose, followed by transcardial perfusion with formalin and saline for histology.

In vitro experiments. Methods for in vitro experiments have been detailed elsewhere (Cox et al., 1992). Briefly, coronal slices from rat auditory cortex were maintained in an interface chamber at $32^{\circ} \mathrm{C}$ in physiological solution (in $\mathrm{mm}$ ): $\mathrm{NaCl}, 125 ; \mathrm{KCl}, 2.5 ; \mathrm{MgSO}_{4}, 1.2 ; \mathrm{CaCl}$, $2.5 ; \mathrm{KH}_{2} \mathrm{PO}_{4}, 1.25 ; \mathrm{NaHCO}_{3}, 25 ;$ glucose, 10 ; gassed with $95 \% \mathrm{O}_{2}$ and $5 \% \mathrm{CO}_{2}$ for $\mathrm{pH} 7.4$. Neurons were impaled with microelectrodes $(4 \mathrm{M}$ $\mathrm{K}^{+}$-acetate, $60-100 \mathrm{M} \Omega$ ), and current clamp recordings were made using an amplifier with an active bridge circuit. Tetanic stimulation consisted of $8-40$ pulses at $20 / \mathrm{sec}, 20-100 \mu \mathrm{A}$, delivered via bipolar electrodes to the deep gray matter, usually several hundred microns ventromedial to the recording site. This site of stimulation lay along the presumed path of NB cholinergic afferents, which enter the lateral neocortex ventrally and then turn dorsally and course in the deep layers of a given coronal plane (Kristt et al., 1985; Saper, 1987). In some cells, 6,7dinitroquinoxaline-2,3-dione (DNQX), D-2-amino-5-phosphonovalerate (APV), and picrotoxin were used to attenuate activity resulting from amino acid transmission. Throughout the Results, all averages are \pm SEM.

\section{Results}

Results from in vivo experiments

In 41 experiments on urethane-anesthetized rats, large-amplitude, $1-5 \mathrm{~Hz}$ fluctuations dominated the local field potential (EEG) recorded in the middle and lower layers (range, 500-1000 $\mu \mathrm{m}$ ) of auditory cortex (Figs. 1-3). Tetanic stimulation of the NB region of the basal forebrain elicited EEG activation (Fig. $1 A ; n=36$ ), resulting in the appearance of higher-frequency EEG components and decreased power in the $1-5 \mathrm{~Hz}$ range (Fig. $1 B$ ). The desynchronization endured for approximately $1-20$ sec, and more intense or longer-duration stimulation desynchronized the EEG for longer periods of time (Fig. 1A). Tetani repeated more frequently than about $0.1 / \mathrm{sec}$ also resulted in longer periods of desynchronization. Recordings from superficial cortical layers revealed EEG fluctuations that were similar in frequency but reduced in amplitude from those in middle and deep cortical layers. In these superficial recordings, NB stimulation generally produced weak or no observable desynchronization of the local EEG. However, continuing the electrode penetration to the middle and deep cortical layers revealed clear NB-mediated desynchronization. These data suggest that the sources of superficial and deep field potentials under the present conditions may not be identical, and that the site of NB-mediated action lies within the deeper layers. However, it is possible that the effects of NB stimulation are only less noticeable superficially, if the sources of superficial field potentials are more widely distributed and/or less synchronized than those deeper within the cortex.

Atropine antagonized the NB-induced EEG desynchronization (Fig. $1 A, B$ ) when administered iontophoretically within the cortex $(20-60 \mathrm{nA} ; n=5)$, directly to the cortical surface (50$320 \mu \mathrm{M} ; n=4)$, or systemically $(3.2-15 \mathrm{mg} / \mathrm{kg} ; n=2)$. In each case, atropine not only blocked EEG desynchronization, but also increased the amplitude and degree of synchronization, implying a tonic action of endogenous ACh. Increasing the intensity of NB stimulation could partly overcome the atropine block. These effects of atropine suggest that NB-mcdiated EEG activation involves muscarinic cholinergic receptors located within the neocortex.

The effectiveness of NB stimulation in eliciting cortical activation varied with the anesthetic used. In urethane-anesthetized animals with clear NB-induced EEG activation, systemic administration of subanesthetic doses of pentobarbital (5.0-8.4 $\mathrm{mg} / \mathrm{kg}$ ) effectively blocked EEG desynchronization withoul increasing EEG synchrony ( $n=3$; not shown). The pentobarbital effect endured for $30-60 \mathrm{~min}$.

Evidence that the tetanus-induced EEG activation primarily involved the subset of NB neurons that project to auditory cortex was obtained in a series of 20 consecutive experiments. In these experiments, the NB stimulating electrode was positioned in a single penetration, to preclude tissue damage from multiple penetrations, and to facilitate accurate determination of stimulation sitcs from histological sections. To facilitate reliable grouping of data across experiments, the rostrocaudal distance of each site from the anterior commissure was determined from histological material. Sites of stimulation that effectively elicited EEG activation lay in the middle and ventral aspects of the globus pallidus and substantia innominata, at an average rostrocaudal distance of $0.77 \mathrm{~mm}$ (range, 0.54-1.04 $\mathrm{mm}$ ) from the anterior commissure (Fig. 2A, upper section). This region contains the magnocellular cholinergic neurons of the NB that project to auditory cortex (Wenk et al., 1980; Saper, 1984; Moriizumi and Hattori, 1992). In contrast, stimulation sites located more rostrally in the NB were less effective in eliciting EEG activation in auditory cortex (Fig. $2 A$, lower section). This finding is consistent with data indicating that the rostral NB projects to other cortical regions (Wenk et al., 1980). Thus, forebrain stimulation that effectively elicited EEG activation in auditory cortex likely involves the NB neurons that project to auditory cortex. The further importance of these data is twofold. First, they suggest that the topographic nature of NB projections to neocortex (McKinney et al., 1983; Rye et al., 1984) could produce localized EEG activation. Second, they indicate that axon fibers passing rostrocaudally through the NB are not responsible for changes in the cortical EEG following tetanic stimulation.

Further evidence that NB neurons, and not fibers of passage, mediated EEG activation was provided by chemical stimulation of the NB region with the excitatory amino acid glutamate. Glutamate infusion $(30-180 \mathrm{nmol})$ via a cannula glued to the stimulating electrodes desynchronized the cortical EEG (Fig. 2B; $n=8$ ). Saline infusion of equal volume produced no effect. In general, glutamate produced weaker cortical activation than did 
A

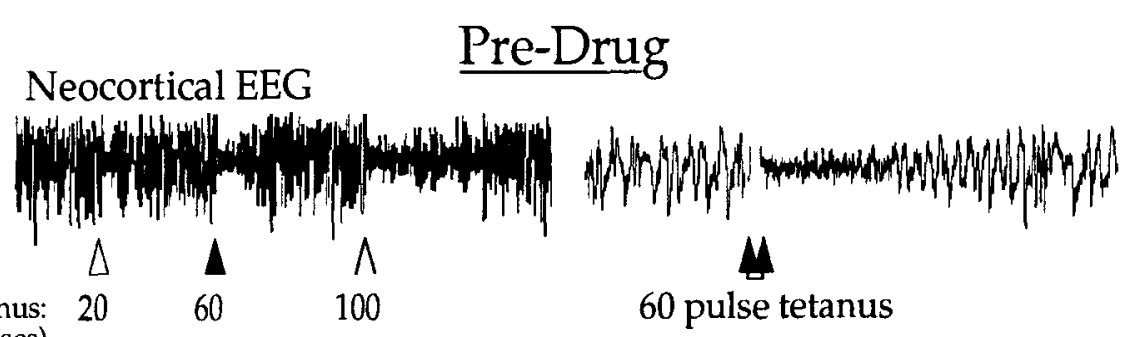

NB tetanus: $20 \quad 60 \quad 100$

60 pulse tetanus
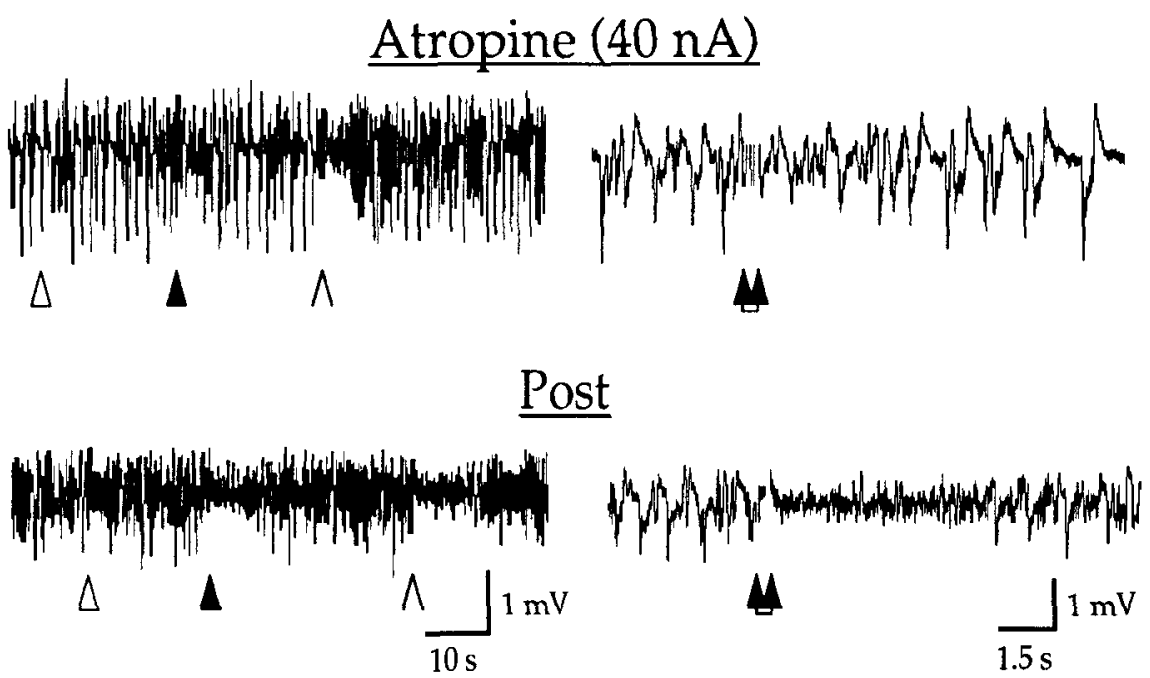

B

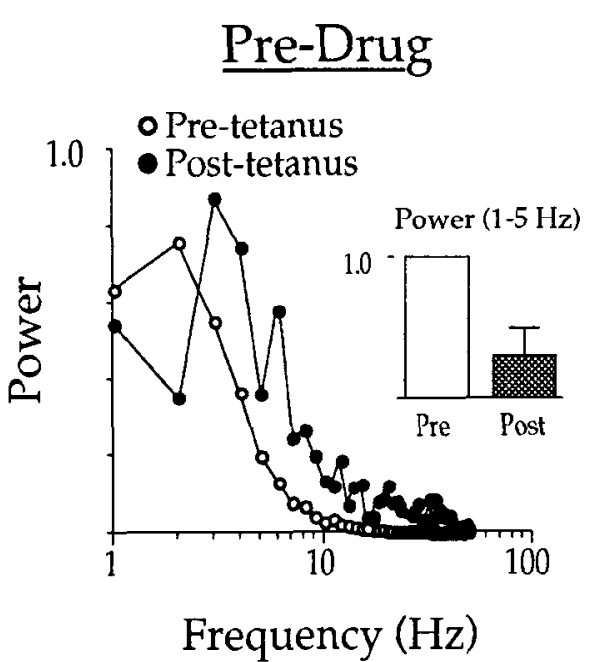

Frequency $(\mathrm{Hz})$

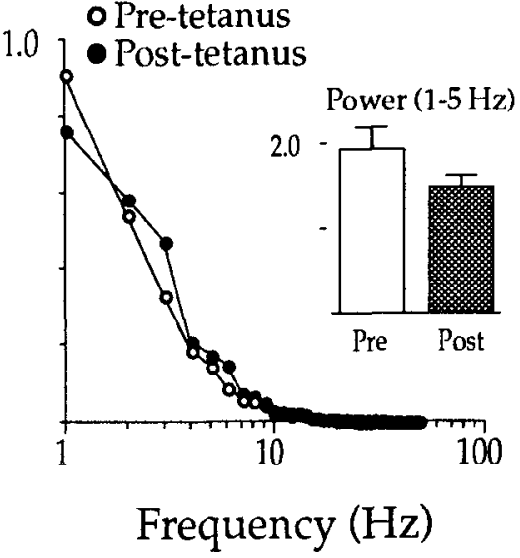

Figure 1. NB stimulation in vivo elicited EEG activation mediated by cortical muscarinic receptors. $A$, NB tetani (200/sec, $500 \mu \mathrm{A})$ of increasing number of pulses (arrowheads) elicited correspondingly longer durations of EEG desynchronization. Effect of 60 pulse tetanus is shown at faster speed to the right (duration of tetanus indicated by arrows; artifacts are blanked). Atropine, administered iontophoretically ( $40 \mathrm{nA}$ ) within auditory cortex, enhanced synchronous oscillations and antagonized the effect of NB stimulation. Increasing stimulus intensity (e.g., 100 pulse stimulus) partly overcame the atropine blockade. Recovery was seen at about $1 \mathrm{hr}($ Post $)$. B, Averaged $(n=5)$ frequency power spectra show that NB stimulation resulted in increased highfrequency components (Pre-drug spectra; individual functions contributing to each average were normalized to the peak power under that condition, i.e., pre- or posttetanus). NB stimulation also produced decreased power in the 1-5 $\mathrm{Hz}$ range (histogram in inset; power normalized to pretetanus value for each experiment). Atropine antagonized the effect of NB stimulation on EEG frequency components and power in the $1-5 \mathrm{~Hz}$ range. Note that the increased EEG amplitude and synchrony under atropine (seen in $A$ ) resulted in increased power in the $1-5 \mathrm{~Hz}$ range relative to control (note change in histogram scale). Data are from five experiments in which (1) atropine was administered within the cortex (either iontophoretically or directly to the cortical surface), and (2) NB-mediated EEG desynchronization endured for longer than $2 \mathrm{sec}$ (to allow for adequate digital sampling). electrical stimulation, a finding that may reflect the difficulty in effectively stimulating cortically projecting NB neurons that are relatively few in number yet distributed over a wide area (Bigl et al., 1982; Saper, 1984). However, the data do suggest that neurons whose somas lie in the NB region mediate activation of the cortical EEG.

Simultaneous extracellular unit and EEG recordings in the cortex showed that at middle and deep (>500 $\mu \mathrm{m})$ recording sites, single- or multiple-unit activity invariably coincided with the negative phase of EEG fluctuations, resulting in a phasic pattern of discharge (Fig. $3 A$ ). Tetanic NB stimulation produced a tonic pattern of unit discharge during EEG activation $(n=$ 16). A return to the phasic discharge pattern occurred as the
EEG resynchronized. Thus, NB stimulation elicited EEG activation, increased single-unit discharge, and a shift from a phasic to a tonic discharge pattern.

Intracellular recordings in vivo revealed that prior to NB stimulation, abrupt, large-amplitude membrane depolarizations appeared to coincide with EEG negativities (Fig. $3 B_{i}$; shown at higher resolution in the lower part of the figure; $n=17)$. NB stimulation produced membrane depolarization of $5.2 \pm 1.9$ $\mathrm{mV}$ (range, $1-10 \mathrm{mV}$ ) (Fig. $3 B_{2}$ ) that lasted for the duration of EEG activation. Small-amplitude, fast (approximately 20-40 $\mathrm{Hz}$ ) fluctuations replaced the abrupt, large-amplitude depolarizations, and were superimposed on the maintained depolarization. After several (1-20) seconds of maintained depolariza- 


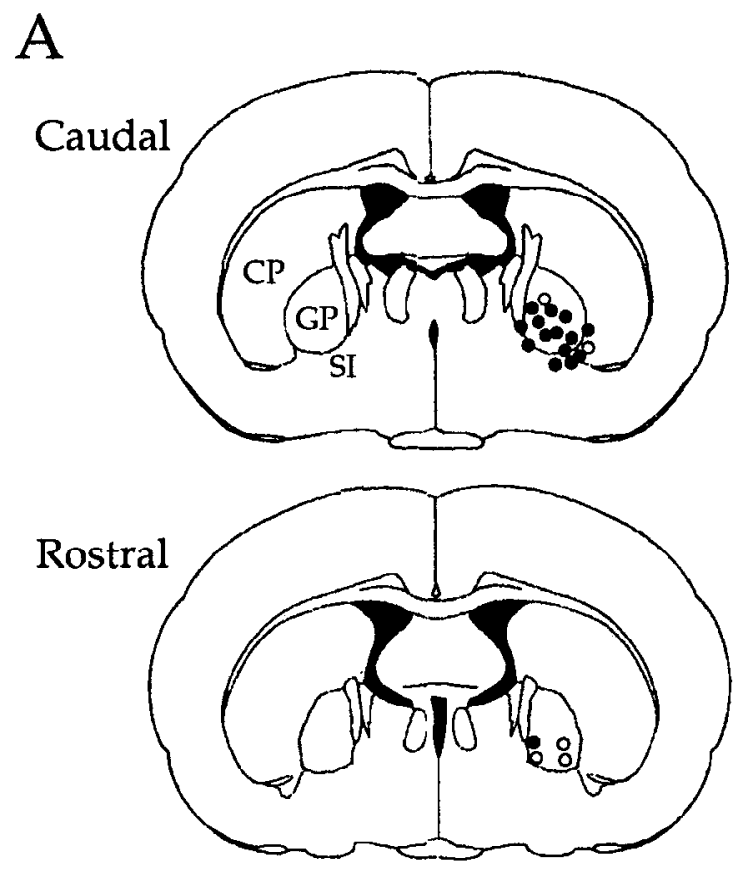

B
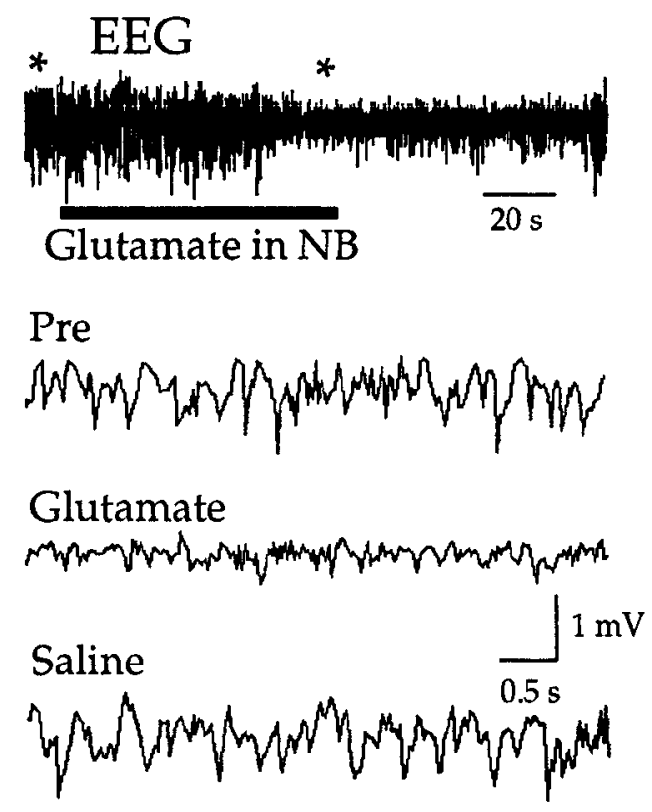

Figure 2. A, Effective (solid circles) and ineffective (open circles) stimulation sites for eliciting EEG activation in 20 consecutive experiments. Caudal stimulation sites (mean rostrocaudal distance from the anterior commissure, $0.77 \mathrm{~mm}$; range, $0.54-1.04 \mathrm{~mm}$ ) were more effective $(87.5$ $\% ; n=14$ of 16 ), whereas rostral stimulation sites (mean distance, 0.28 $\mathrm{mm}$; range, $0.08-0.46 \mathrm{~mm}$ ) were less effective ( $25 \% ; n=1$ of 4$)$. Effective stimulation sites lay in middle and ventral aspects of the caudal globus pallidus (GP) and substantia innominata (SI), source of the NB cholinergic projection to auditory cortex (Wenk et al., 1980; Saper, 1984). Atlas sections modified from Paxinos and Watson (1986). CP, caudate putamen. $B$, Glutamate ( $180 \mathrm{nmol}$ in saline), delivered via a 30 gauge cannula attached to the stimulating electrode, desynchronized the EEG for $>1$ min (recovery can be seen at end of trace). Portions of the EEG before and during glutamate-induced desynchronization are marked by asterisks and shown below at higher resolution. Subsequent saline infusion of equal volume was without effect. tion, the membrane potential returned to its original level, and the EEG and intracellular fluctuations simultaneously reverted to their original patterns. Subsequently, steady current injection through the intracellular recording electrode showed that membrane depolarization, per se, did not alter the pattern or frequency of membrane potential fluctuations, but only increased the probability of cell discharge, which occurred in a phasic pattern (Fig. $3 B_{3}$ ). Tetanic NB stimulation from this depolarized level did reveal the excitatory nature of NB actions, which produced increased, tonic discharge (Fig. $3 B_{4}$ ).

Neurons that did not discharge spontaneously at rest, or discharged infrequently, allowed the modification of subthreshold membrane potential fluctuations to be clearly observed (Fig. $3 B$; $n=8$ ). These neurons had resting membrane potentials of -68 $\pm 2.7 \mathrm{mV}$ and spike amplitudes (measured from firing threshold) of $68 \pm 1.7 \mathrm{mV}$. In spontaneously firing neurons (resting membrane potential, -40 to $-60 \mathrm{mV} ; n=9$ ), NB stimulation appeared to modify membrane potential activity similarly, resulting in depolarization and increased firing frequency. Note that in neurons that discharged either spontaneously or during steady current injection, the changes in firing patterns before (Fig. $3 B_{3}$ ) and after (Fig. $3 B_{4}$ ) NB stimulation resembled the phasic to tonic changes in extracellularly recorded firing patterns (Fig. 3A).

Taken together, the data obtained in vivo indicate that NBinduced EEG activation appears to involve a process mediated by cortical muscarinic receptors that results in modification of membrane potential fluctuations in cortical neurons. The modification of membrane potential fluctuations alters the pattern of spike discharge, from phasic to tonic firing. This process may be neuromodulatory, for while it is usually accompanied by membrane depolarization, it appears to act independently of depolarization, and results in relatively enduring changes in neuronal activity. To study more closely the modification of neocortical neurons by endogenous $\mathrm{ACh}$, we turned to the in vitro neocortical slice preparation.

\section{Results from in vitro experiments}

Evidence for neocortical actions of endogenous $\mathrm{ACh}$ was obtained from 50 neurons in the auditory cortical slice. These neurons had a mean resting potential of $-75 \pm 1.2 \mathrm{mV}$, spike amplitude of $72 \pm 1.3 \mathrm{mV}$ (measured from firing threshold of $-58 \pm 1.5 \mathrm{mV}$ ), and apparent input resistance of $37 \pm 3.0 \mathrm{M} \Omega$. Neurons never discharged spontaneously, nor did they display prominent membrane potential fluctuations at the resting membrane potential. Based on electrophysiological criteria (Connors et al., 1982; McCormick et al., 1985; Chagnac-Amitai et al., 1990; Mason and Larkman, 1990) and location in the slice (range, 600-1300 $\mu \mathrm{m}$ from the pial surface), thesc ncurons were likely to be pyramidal neurons from layers 5 and 6 .

At the resting membrane potential, tetanic stimulation of the deep cortical gray matter elicited rapid membrane depolarization and spiking followed by an afterhyperpolarization and, occasionally, a small-amplitude slow depolarization. When tetanic stimulation was presented during steady membrane depolarization to near threshold by intracellular current injection, the slow membrane depolarization was more readily apparent (cf. Fig. $5 B$; peak amplitude, $2.9 \pm 0.4 \mathrm{mV}$, range $1-9 \mathrm{mV}$; duration, $174 \pm 24 \mathrm{sec}$, range $35 \mathrm{sec}$ to $5 \mathrm{~min} ; n=17$ ). In some cells, a clear depolarization only occurred in the presence of the anticholinesterase eserine $(1.0 \mu \mathrm{M} ; n=2)$, whereas in other cells eserine increased the magnitude of the slow depolarization (to 
A

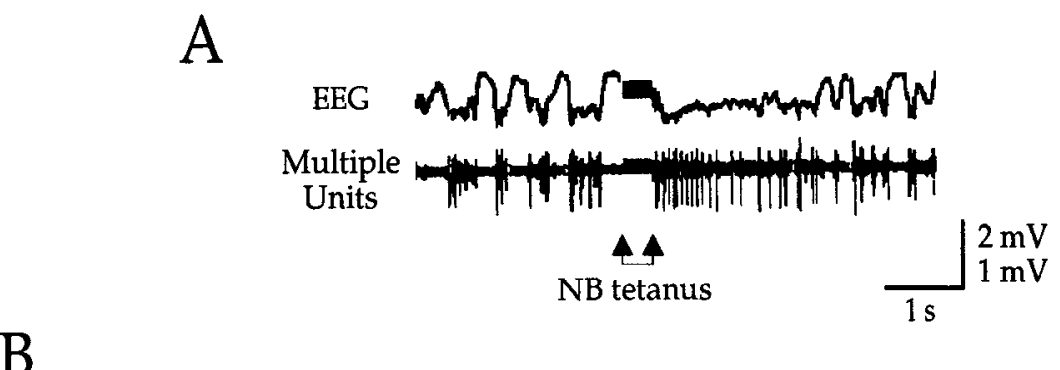

B

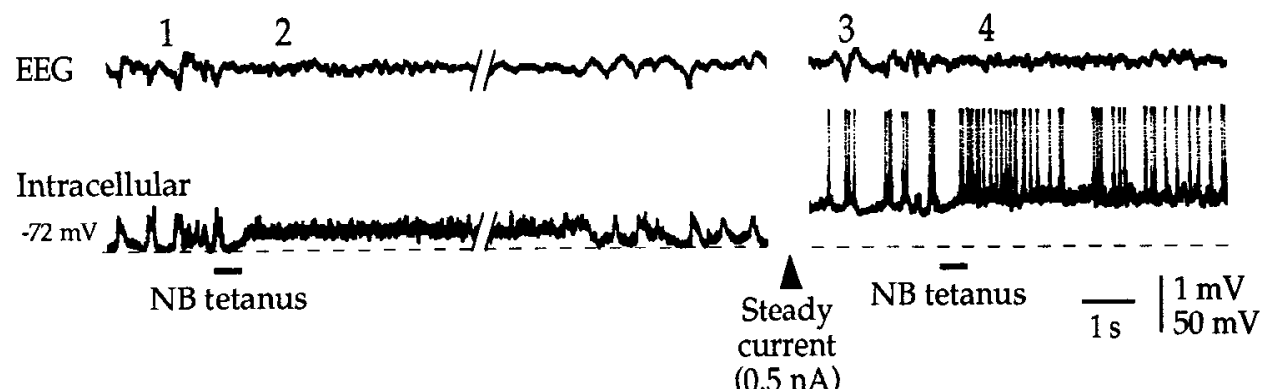

1

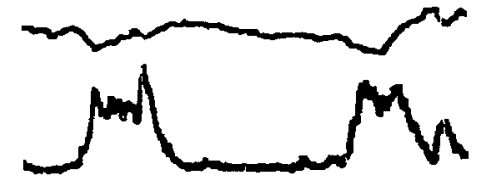

3

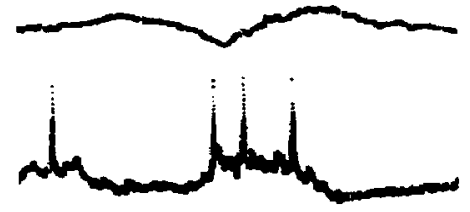

2

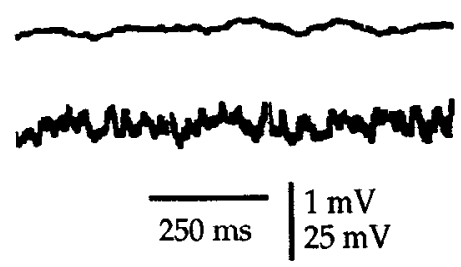

4

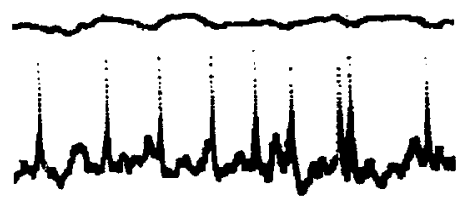

Figure 3. NB stimulation in vivo simultaneously activated the cortical EEG and altered the frequency and pattern of spike discharge and subthreshold neural activity. $A$, Extracellularly recorded unit activity (depth, $987 \mu \mathrm{m}$ from the pia) coincided with the negative phase of EEG fluctuations, resulting in a phasic discharge pattern (prior to the tetanus). NB tetanus (artifact blanked) elicited EEG activation and tonic unit discharge. Note negative shift of EEG during desynchronization (EEG is DC-coupled in this trace only). Unit and EEG activity reverted to their original patterns within seconds. $B$, Simultaneous EEG and intracellular recording (depth, $571 \mu \mathrm{m}$ ) prior to tetanus revealed abrupt membrane depolarizations from the resting membrane potential $(-72 \mathrm{mV}$ ) that coincided with negative EEG fluctuations (top left panel; EEG on top, transmembrane potential on bottom; shown below in 1 at higher resolution). NB tetanus elicited EEG activation, a $10 \mathrm{mV}$ depolarization, and fast, small-amplitude membrane potential fluctuations (2). EEG and intracellular activity recovered to original patterns of fluctuations within about 10 sec (gap in record indicates a $4 \mathrm{sec}$ interval). Subsequent steady injection of intracellular current $(0.5 \mathrm{nA}$; top right panel $)$ produced membrane depolarization of about $10 \mathrm{mV}$ greater than that produced by the NB tetanus; however, this did not alter the pattern or frequency of oscillations (3). Steady current injection did result in spontaneous membranc depolarizations cliciting spikes in a phasic discharge pattern, and revealed the excitatory nature of NB actions; that is, the NB-mediated increased frequency of membrane fluctuations gave rise to increased spike discharge in a tonic firing pattern (4). Epochs of EEG and intracellular activity (labeled $1-4$ ) are shown below with greater resolution; spikes are truncated in 3 and 4.

$241 \pm 66 \%$ of control; $n=3$ ), suggesting the involvement of endogenous $\mathrm{ACh}$. The muscarinic receptor antagonists atropine $(1.0 \mu \mathrm{M} ; n=3)$ or pirenzepine $(0.1-1.0 \mu \mathrm{M} ; n=8)$ attenuated the slow depolarization (by $85 \pm 6 \%$ ), indicating cholinergic action via muscarinic receptors. The voltage dependence and pharmacological characteristics of the tetanus-induced slow depolarization resembled the characteristics of depolarizations induced by muscarinic agonists acting on cortical neurons (Cole and Nicoll, 1984b; McCormick and Prince, 1986), as well as the characteristics of muscarinic synaptic activity in diverse regions of the CNS and PNS (Ashe and Yarosh, 1984; Cole and Nicoll, 1984a; Misgeld, 1989; Benardo, 1991). Together, these data indicate the presence in auditory neocortex of a slow EPSP mediated by $\mathrm{ACh}$ acting at muscarinic receptors.
Two actions of the tetanus-induced slow depolarization are particularly relevant to the present discussion on control of neocortical neural oscillations. First, the slow depolarization modified the characteristics of neurons that generated either single or repetitive burst discharges. At membrane potentials close to rest (about $-75 \mathrm{mV}$ ), such neurons responded to depolarizing current pulses either with a single burst of action potentials (two or three spikes riding on a depolarizing envelope), or with rhythmic, repetitive bursts at $4.7 \pm 0.9 \mathrm{~Hz}$ (Fig. $4 A ; n=26$ ) (see also McCormick et al., 1985; Agmon and Connors, 1989; Chagnac-Amitai et al., 1990; Silva et al., 1991). During steady membrane depolarization by intracellular current injection, current pulses elicited only single-spike discharge (i.e., no bursts), which occurred at a higher frequency $(10-20 \mathrm{~Hz})$ 


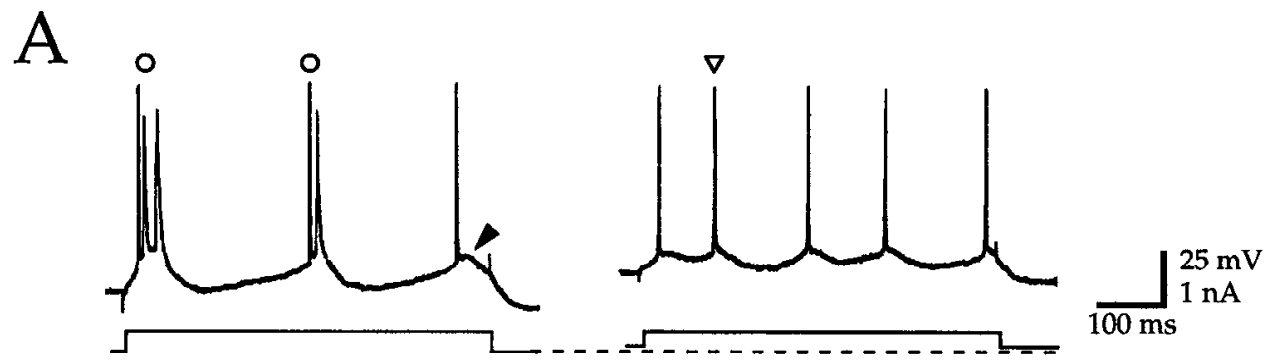

B

Pre-Tetanus Post-Tetanus

Pre-Drug
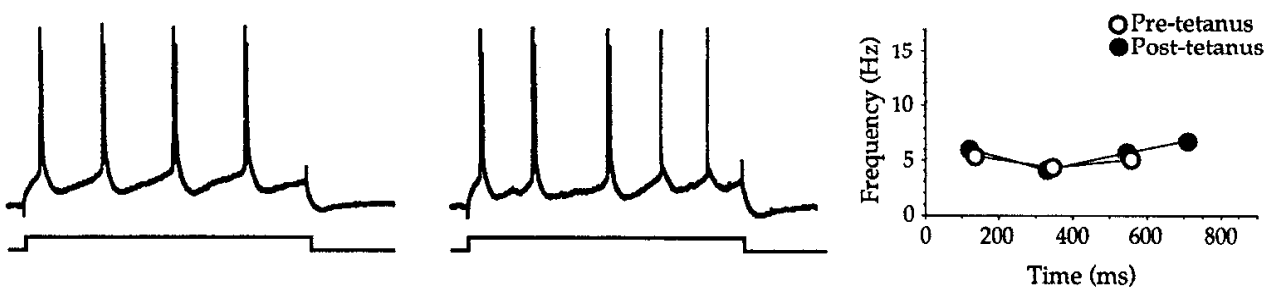

Eserine $(1 \mu \mathrm{M})$
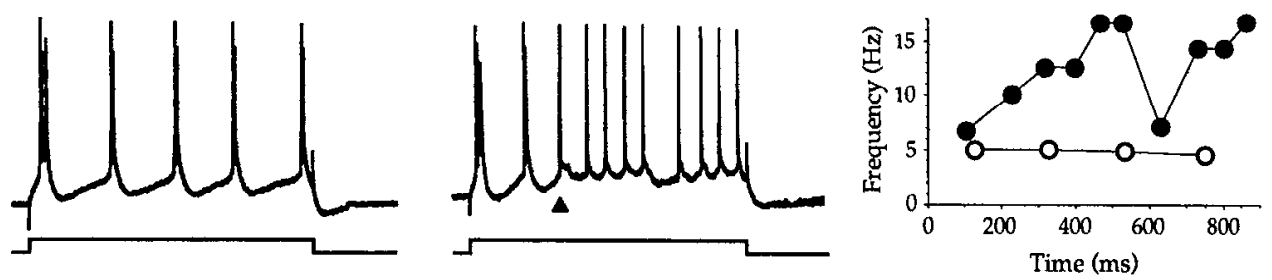

\section{+ Atropine $(1 \mu \mathrm{M})$}
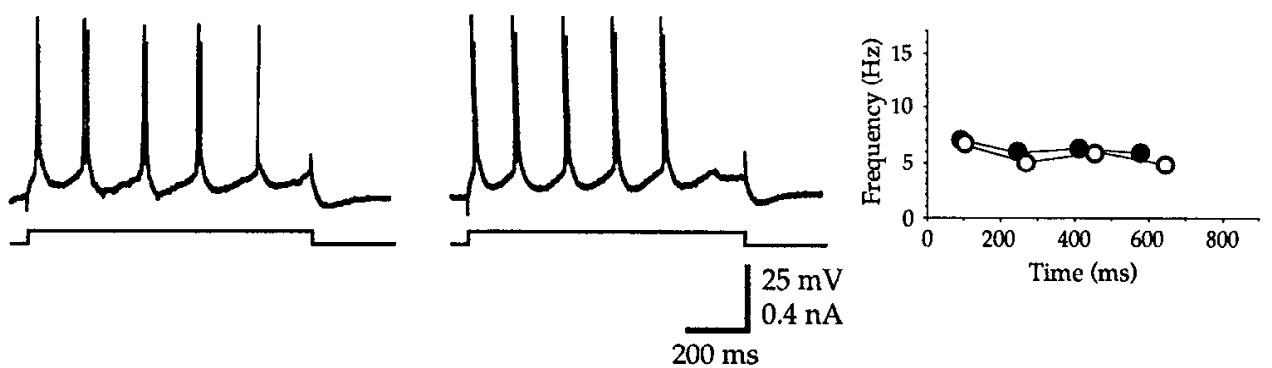

Figure 4. Muscarinic action in vitro resulted in switch from low-frequency bursting to higher-frequency single-spike discharge in rhythmic-bursting neurons. $A$, Depolarizing current pulse from rest $(-77 \mathrm{mV})$ elicited rhythmic, repetitive bursts of two or three spikes (open circles), with an afterdepolarization (solid arrowhead) following a solitary spike. During steady depolarization, a current pulse elicited only single spikes (open triangle) without prominent afterdepolarizations. $B$, In the same cell, a longer $(900 \mathrm{msec})$ current pulse elicited rhythmic, repetitive bursting at about $5 \mathrm{~Hz}$. Tetanic stimulation ( 40 pulses, 20/sec, $100 \mu \mathrm{A}$ ) appeared to produce a reduced tendency to burst since the current pulse elicited two single spikes and one fewer burst. The discharge frequency of the neuron is quantified in the graph to the right of the traces, which indicates firing frequency throughout the $900 \mathrm{msec}$ current pulse determined from each interburst (for bursts) or interspike (for single spikes) interval. In the predrug condition, the tetanus did not appreciably change the frequency of discharge, which remained at about $5 \mathrm{~Hz}$ despite the appearance of single spike activity. Eserine clearly enhanced the effect of the tetanus, resulting in the current pulse eliciting many single spikes and fewer bursts. Note the abrupt shift from bursting to single-spike firing modes (arrowhead), and the relative absence of both afterdepolarizations and large afterhyperpolarizations during single spike firing. As indicated by the graph, the tetanus changed the discharge frequency from about $5 \mathrm{~Hz}$ to up to $17 \mathrm{~Hz}$ during single-spike activity. Correction for the slight $(2 \mathrm{mV})$ depolarization elicited by the tetanus did not change the response to current pulses (not shown). Atropine completely blocked the effects of the tetanus and eserine.

than the rhythmic bursts (Fig. 4A). Thus, these neurons can exhibit one of two modes of firing, either bursting or single spike, depending on the membrane potential. However, following tetanic stimulation at membrane potentials close to rest, current pulses elicited more single spikes and a reduced tendency to burst, despite little change (e.g., $0-2 \mathrm{mV}$ ) in the baseline membrane potential (Fig. $4 B ; n=12$ ). Eserine $(1 \mu \mathrm{M} ; n=3$ ) clearly enhanced this effect, indicating action of endogenous ACh. Muscarinic antagonists $(1 \mu \mathrm{M}$ atropine or $0.1-1.0 \mu \mathrm{M}$ pirenzepine; $n$ $=3$ ) blocked the effect, indicating the involvement of muscarinic 


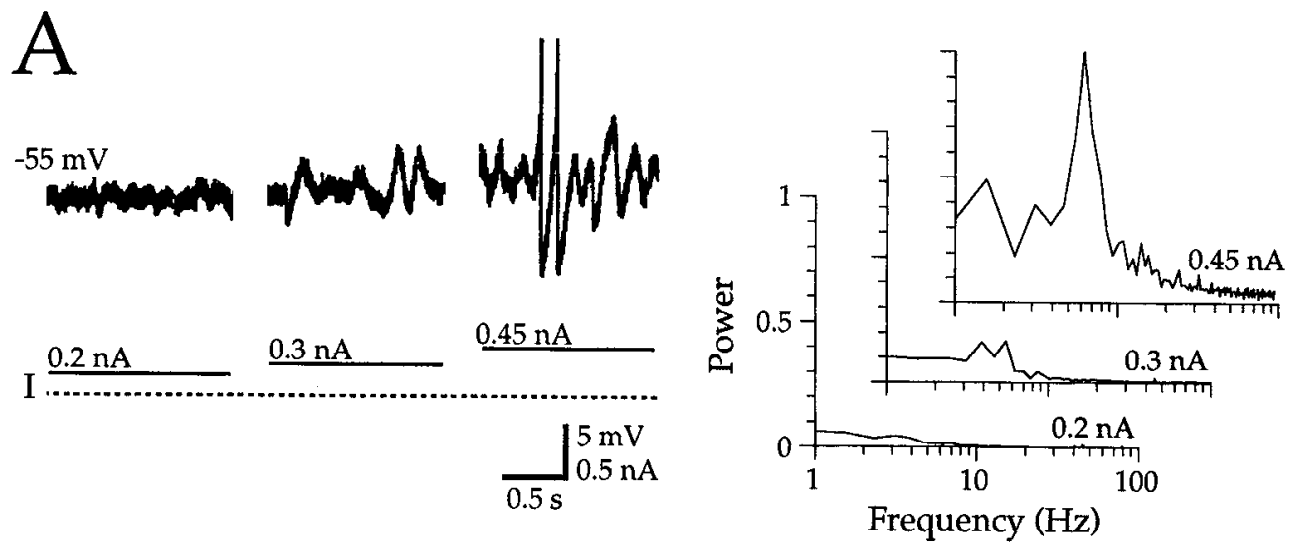

B
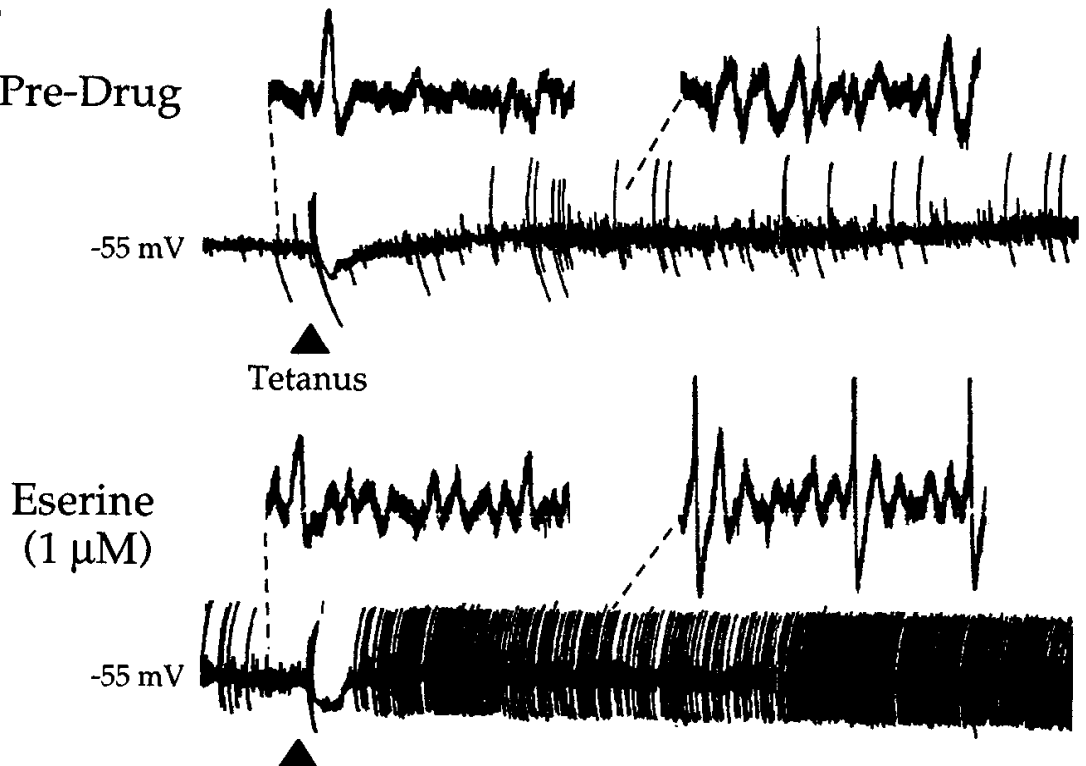

Tetanus

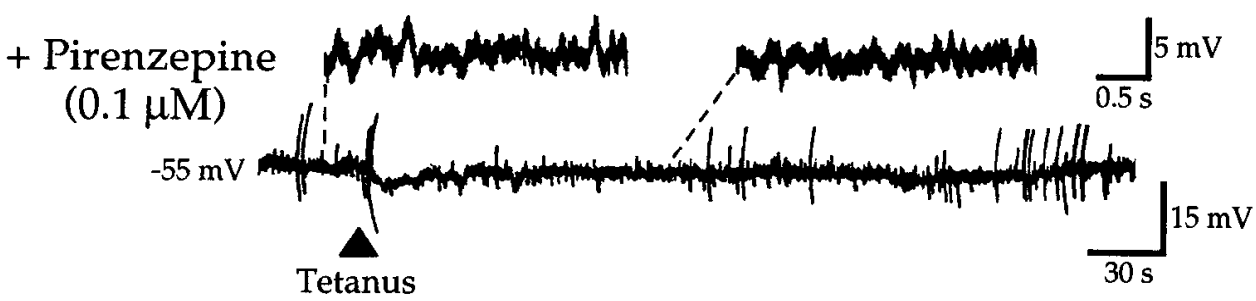

Figure 5. Muscarinic facilitation of intrinsic membrane potential oscillations in vitro. $A$, Membrane depolarization through passage of current ( $I$; broken line indicates zero current) through the recording electrode resulted in the appearance of membrane potential oscillations that increased in frequency and amplitude, and could clicit spikes (truncated in figure), with increasing depolarization. Power spectra derived from records at each level of injected current show the emergence of oscillations that peak at about $6 \mathrm{~Hz}$ (spectra are derived from 15-20 sec epochs and are normalized to the peak value of the function for $0.45 \mathrm{nA}$ ). $B$, In the same cell, at a membrane potential where oscillations were not prominent, tetanic stimulation elicited a slow hyperpolarization followed by a smallamplitude, long-lasting depolarization and the appearance of membranc potential oscillations (shown at higher resolution in inset). Following recovery, bath application of eserine by itself resulted in the appearance of membrane oscillations (i.e., oscillations can be seen prior to tetanus). Subsequently, the tetanus produced sustained spiking elicited by oscillations. Pirenzepine blocked the effects of both eserine and the tetanus.

receptors. Thus, endogenous muscarinic actions can shift the mode of cell firing, from low-frequency bursting to higher-frequency, single-spike discharge.

The effectiveness with which tetanic stimulation reduced burst generation differed between rhythmically bursting and single burst neurons. Suppression of burst generation by tetanic stimulation occurred invariably in rhythmically bursting neurons $(100 \% ; n=7$ of 7$)$. These neurons were located primarily in a narrow region of cortex $800-1000 \mu \mathrm{m}$ from the pial surface. Tetanus-induced burst suppression occurred less frequently in single burst neurons $(27 \% ; n=3$ of 11$)$; such neurons were not preferentially distributed in the cortex. These data suggest that the modification of rhythmic burst generation is an important feature of endogenous cholinergic actions, and one that is pref- erentially directed at one class of neuron, the rhythmically bursting pyramidal neuron found in cortical layer 5 (Agmon and Connors, 1989; Chagnac-Amitai et al., 1990; Mason and Larkman, 1990).

A second action of the tetanus-induced slow depolarization was to modify intrinsic membrane potential oscillations. In many neurons, depolarization to near firing threshold elicited oscillations $(5-10 \mathrm{~Hz})$ that increased in frequency and amplitude with increasing depolarization (Fig. $5 A ; n=42$ ) (cf. Leung and Yim, 1991; Llinas et al., 1991; Silva et al., 1991). The oscillations persisted in the presence of agents that attenuate amino acid-mediated synaptic transmission $(10 \mu \mathrm{M}$ DNQX, $100 \mu \mathrm{M}$ APV, $10 \mu \mathrm{M}$ picrotoxin; $n=9$ ), but were blocked by tetrodotoxin $(1 \mu \mathrm{M} ; n=2)$. Since fast synaptic transmission in auditory cortex 
is mediated by amino acids (Cox et al., 1992), these findings support the intrinsic nature of the oscillations, and implicate voltage-dependent $\mathrm{Na}^{+}$currents in their generation.

Tetanic stimulation facilitated the frequency and amplitude of intrinsic oscillations, sometimes resulting in spike discharge (Fig. $5 B ; n=26$ ). The facilitation of oscillations could be partly attributed to tetanus-induced slow depolarization; however, in the presence of eserine, oscillations could appear prior to the tetanus at membrane potentials where they were not previously seen (Fig. $5 B$ ). This suggests that potentiation of ongoing cholinergic activity resulted in a decreased threshold for oscillations. Subsequent tetanic stimulation in eserine resulted in further facilitation of the oscillations, which sometimes led to sustained repetitive discharge $(n=9)$. Atropine or pirenzepine did not attenuate oscillations, but did reduce the effects of eserine and tetanic stimulation $(n=9)$. Thus, muscarinic synaptic actions could facilitate the appearance and magnitude of intrinsic membrane potential oscillations.

\section{Discussion}

The present results indicate that NB stimulation in vivo(1) elicits EEG activation via cortical muscarinic receptors, (2) depolarizes cortical neurons, and (3) produces a change in membrane potential fluctuations from large-amplitude, slow oscillations to low-amplitude, fast oscillations. The change in membrane potential oscillations results in a shift in firing pattern, from phasic to tonic discharge. In the in vitro neocortex, actions of endogenous $\mathrm{ACh}$ at muscarinic receptors (1) reduce slow, rhythmic burst discharge and facilitate higher-frequency, single-spike discharge in burst-generating neurons, and (2) facilitate the appearance and magnitude of intrinsic membrane potential oscillations. These data suggest that $\mathrm{NB}$ activity elicits a cortical cholinergic synaptic potential that induces EEG activation via, at least partly, muscarinic modulation of intrinsic neocortical oscillations and firing modes.

The effect of forebrain stimulation appears to involve NB neurons that project to auditory cortex. Anatomical studies that combine retrograde labeling with identification of cholinergic neurons indicate that the NB cholinergic projection to rat auditory cortex arises from neurons in the medial and ventral portions of the caudal globus pallidus, and adjacent portions of the substantia innominata and internal capsule (Bigl et al., 1982; Saper, 1984; Moriizumi and Hattori, 1992). Electrolytic lesions of this region significantly reduce cholinergic markers in auditory cortex (Wenk et al., 1980). In the present study, electrical or chemical stimulation of this NB region effectively activated the EEG in auditory cortex, using tetanus parameters or glutamate doses that elicit cortical ACh release (Kurosawa et al., 1989). In contrast, stimulation of the rostral NB was relatively ineffective in activating auditory cortex, a finding consistent with rostral NB projections to visual, but not auditory, cortex (Wenk et al., 1980). These data, plus those indicating that cortical administration of atropine blocked the activating effect of NB stimulation, implicate the NB cholinergic projection to auditory cortex in mediating EEG activation. Further, the effectiveness of caudal, but not rostral, NB stimulation suggests that NB neurons could exert local, as well as global, control over neocortical activity.

The present findings support the hypothesis that the NB forms the cortical link of a cholinergic ascending reticular activating system (Shute and Lewis, 1967; Detari and Vanderwolf, 1987; Steriade and Buzsaki, 1990). While stimulation of the brainstem reticular formation results in cortical activation and $\mathrm{ACh}$ release (Moruzzi and Magoun, 1949; Kanai and Szerb, 1965; Celesia and Jasper, 1966), there are few direct cholinergic projections from the brainstem to cortex (Wainer and Mesulam, 1990). Rather, the major cholinergic projection to cortex arises from the $\mathrm{NB}$, which in turn receives inputs from a wide variety of structures, including the reticular formation (Wainer and Mesulam, 1990). Thus, direct cholinergic control of cortical activation is probably mediated via the NB (Detari and Vanderwolf, 1987; Steriade and Buzsaki, 1990; present results).

While the NB likely plays an important role in cortical activation, several neural systems that ascend through the neuraxis in parallel may contribute to activation under different circumstances. Stimulation of mesopontine cholinergic nuclei in the brainstem results in cortical activation, an effect that persists even after excitotoxic lesions of the NB (Steriade et al., 1991). Since mesopontine cholinergic nuclei primarily innervate the thalamus, this suggests that thalamocortical projections, which may utilize glutamate as a neurotransmitter (Fox and Armstrong-James, 1986; Tsumoto et al., 1986; Hicks et al., 1991), contribute to processes of activation. Non-cholinergic brainstem nuclei such as the locus coeruleus and raphe nuclei that project diffusely to neocortex have also been implicated in activation (Vanderwolf, 1988; Berridge and Foote, 1991). How and when these neural systems contribute to processes of activation are unclear; however, the putative neurotransmitters released by these systems may converge at the cortex onto common cellular mechanisms. That is, norepinephrine, serotonin, and metabotropic actions of glutamate all can exert some neuromodulatory effects similar to those mediated by $\mathrm{ACh}$ acting at muscarinic receptors (Nicoll, 1988; McCormick, 1989; Baskys, 1992). Thus, final control over cortical excitability and rhythms may depend on the interplay of several neural systems, of which NB neurons form the primary source of direct ACh-mediated cortical actions.

Known muscarinic actions of exogenous or endogenous $\mathrm{ACh}$ on cortical neurons include voltage-dependent membrane depolarization and increased input resistance, probably due to decreased $\mathrm{K}^{+}$conductance (Krnjevic et al., 1971; Halliwell and $\Lambda$ dams, 1982; Cole and Nicoll, 1984a,b; McCormick and Prince, 1986). Thus, while cholinergic actions and spontaneous membrane potential oscillations are reduced at the large resting potentials found in vitro, both occur and can interact upon membrane depolarization in vitro, or at the lesser membrane potentials found in vivo. In light of the voltage dependence of ACh actions, the blockade of NB-induced EEG activation by pentobarbital administration may be due to the hyperpolarizing effect of barbiturates (Nicoll and Madison, 1982), which could move the membrane potential out of the voltage range for effective ACh action.

An important finding of the present study, obtained both in vivo and in vitro, is that apparent neuromodulatory actions of endogenous $\mathrm{ACh}$ can modify the discharge mode of cortical neurons. Bursting and single-spike firing modes are characteristic of some neurons in the neocortex and thalamus (Connors et al., 1982; Jahnsen and Llinas, 1984; McCormick et al., 1985). In such neurons, membrane depolarization results in the transition from bursting to single-spike firing modes. The present study indicates that similar changes can also be produced by $\mathrm{ACh}$, independently of changes in the resting membrane potential, but perhaps dependent on the presence of other depolarizing inputs that move the membrane potential within the range of 
voltage-dependent cholinergic actions. These data provide evidence for neuromodulatory actions of ACh acting via muscarinic cholinergic receptors. It is probable that such changes are integral to the functional relevance of cortical activation. For example, the transition from sleep to waking is associated with a change in firing pattern of cortical neurons from bursting to single spike, and a concurrent increase in responsiveness to afferent stimuli (Livingstone and Hubel, 1981). Notably, NB actions that elicit neocortical activation also facilitate cortical responsiveness to thalamic inputs (Metherate and Ashe, 1991).

Since low-frequency EEG activity under urethane anesthesia shares physiological and pharmacological characteristics with slow delta waves that occur during sleep (Fox and ArmstrongJames, 1986; Armstrong-James and Fox, 1988), data from the present study can be used to hypothesize a cellular basis and functional significance of EEG activation. For example, during slow waves, cortical neurons may discharge to excitatory inputs only during depolarizing phases of membrane potential fluctuations, and therefore display poor responsiveness to afferent stimuli (Steriade and McCarley, 1990). Muscarinic neuromodulation, generated by NB activity, could reducc slow oscillations and burst generation, and facilitate higher-frequency $(\sim 10$ $\mathrm{Hz}$ ) intrinsic oscillations and single-spike discharge. These actions would make neurons more responsive to afferent stimuli, and contribute to higher-frequency EEG oscillations (e.g., in the alpha, or $8-12 \mathrm{~Hz}$, range) of waking states.

Of particular interest is the consistent modification by endogenous ACh of rhythmic-bursting neurons. Correlative anatomical and physiological studies indicate that such neurons are invariably pyramidal neurons located in cortical layer 5 (Agmon and Connors, 1989; Chagnac-Amitai et al., 1990; Mason and Larkman, 1990). Of the cortical laminae, this region appears to have an intrinsic capacity to generate rhythmic field potential oscillations (Connors, 1984; Steriade et al., 1990; Silva et al., 1991), a finding that has led to a hypothesized pacemaker function for layer 5 bursting neurons (Connors, 1984; Silva et al., 1991). These neurons also have axonal arborizations that largely remain within layer 5 (Chagnac-Amitai et al., 1990), and may therefore mediate synchronization of intralaminar neural activity. Notably, when intracortical inhibitory mechanisms are slightly depressed in vitro, these neurons are excited in phase with rhythmic field potential oscillations, whereas other putative pyramidal neurons are generally inhibited, suggesting that layer 5 bursting neurons may mediate synchronized bursts (ChagnacAmitai and Connors, 1989). Since rhythmic-bursting neurons discharge in bursts at a frequency of about $5 \mathrm{~Hz}$, within the range of slow EEG waves, and discharge in the single-spike mode at higher frequencies $(10-20 \mathrm{~Hz})$ corresponding to those of the activated EEG, neocortical rhythms may reflect, at least in part, the firing mode of burst neurons. Release of ACh from the terminals of NB neurons could shift the firing mode from bursting to single spike, reducing synchronous activity in layer 5. Thus, cortical activation could reflect cholinergic modification of an intrinsic cortical pacemaker.

Finally, this study reveals several clues as to the nature of the cholinergic involvement in higher cognitive functions. It is well established that a significant NB and cholinergic deficit parallels the cognitive dysfunction in Alzheimer's disease (Perry et al., 1978; Whitehouse et al., 1982; Sims et al., 1983). Since the NB likely mediates cortical activation, loss of NB neurons could underlie the increased delta $(1-5 \mathrm{~Hz})$ power and decreased alpha $(8-12 \mathrm{~Hz}$ ) power observed in the EEG of awake Alzheimer's patients (Mody et al., 1991). However, recent findings have placed greater emphasis for cognitive function on cortical oscillations near the $20-40 \mathrm{~Hz}$ frequency range. These higherfrequency cortical oscillations occur in attentive humans and animals, and during sensory stimulation can be transiently synchronized among cortical regions (Freeman and Skarda, 1985; Eckhorn et al., 1988; Gray and Singer, 1989; Engel et al., 1991; Pantev et al., 1991; Ribary et al., 1991). These fast oscillations are hypothesized to contribute to the perception of sensory stimuli by functionally "binding" cortical regions that subserve complementary sensory functions (Eckhorn et al., 1988; Crick and Koch, 1990; Engel et al., 1991). Notably, it appears that cortical $40 \mathrm{~Hz}$ oscillations are also reduced in Alzheimer's disease ( $\mathrm{Ri}$ bary et al., 1991).

In light of the possible significance of fast cortical oscillations, the present demonstration of NB-elicited $20-40 \mathrm{~Hz}$ membrane potential fluctuations is of particular interest. The NB appears to be optimally situated to evaluate sensory stimuli for significance, and to regulate cortical responsiveness accordingly. While NB neurons do not normally respond to sensory stimuli (Lamour et al., 1986), they may do so when the stimuli are behaviorally meaningful (Rigdon and Pirch, 1986; Richardson and DeLong, 1990). Activation of the NB by significant stimuli could therefore result in high-frequency oscillations that would optimize cortical responsiveness. Due to its widespread projections, the NB could coordinate cortical oscillations among diverse cortical regions, binding these regions into larger, functionally significant networks (Freeman and Skarda, 1985; Eckhorn et al., 1988; Gray and Singer, 1989; Weinberger et al., 1990; Engel et al., 1991).

In summary, the findings of this study suggest cellular bases for the involvement of the NB cholinergic system in arousal as well as in higher cognitive functions. It is possible that subsequent investigations may reveal that seemingly different NB functions actually reflect a continuum of actions. In any case, understanding the cellular basis of NB function, as well as the basis of NB dysfunction, will be a priority for futurc rescarch.

\section{References}

Agmon A, Connors BW (1989) Repetitive burst-firing neurons in the deep layers of mouse somatosensory cortex. Neurosci Lett 99:137141

Armstrong-James M, Fox K (1988) Evidence for a specific role for cortical NMDA receptors in slow-wave sleep. Brain Res 451:189196.

Ashe JH, Yarosh CA (1984) Differential and selective antagonism of the slow-inhibitory postsynaptic potential and slow-excitatory postsynaptic potential by gallamine and pirenzepine in the superior cervical ganglion of the rabbit. Neuropharmacology 23:1321-1329.

Baskys A (1992) Metabotropic receptors and "slow" excitatory actions of glutamate agonists in the hippocampus. Trends Neurosci 15:9296.

Belardetti F, Borgia R, Mancia M (1977) Proencephalic mechanisms of ECoG desynchronization in cerveau isole cats. Electroencephalogr Clin Neurophysiol 42:213-235.

Benardo LS (1991) Acetylcholine and norepinephrine mediate slow synaptic potentials in normal and epileptic neocortex. Neurosci Lett 126:137-140.

Berridge CW, Foote SL (1991) Effects of locus coeruleus activation on electroencephalographic activity in neocortex and hippocampus. J Neurosci 11:3135-3145.

Bigl V, Woolf NJ, Butcher LL (1982) Cholinergic projections from the basal forebrain to frontal, parietal, temporal, occipital, and cingulate cortices: a combined fluorescent tracer and acetylcholinesterase analysis. Brain Res Bull 8:727-749.

Buzsaki G, Bickford RG, Ponomareff G, Thal LJ, Mandel R, Gage FH 
(1988) Nucleus basalis and thalamic control of neocortical activity in the freely moving rat. $J$ Neurosci 8:4007-4026.

Casamenti F, Deffenu G, Abbamondi A, Pepeu G (1986) Changes in cortical acetylcholine output induced by modulation of the nucleus basalis. Brain Res Bull 16:689-695.

Celesia GG, Jasper HH (1966) Acetylcholine released from cerebral cortex in relation to state of activation. Neurology (Minneap) 16: $1053-1070$.

Chagnac-Amitai Y, Connors BW (1989) Synchronized excitation and inhibition driven by intrinsically bursting neurons in neocortex. $J$ Neurophysiol 62:1149-1162.

Chagnac-Amitai Y, Luhmann HJ, Prince DA (1990) Burst generating and regular spiking layer 5 pyramidal neurons of rat neocortex have different morphological features. J Comp Neurol 296:598-613.

Cole AE, Nicoll RA (1984a) Characterization of a slow cholinergic post-synaptic potential recorded in vitro from rat hippocampal pyramidal cells. I Physiol (Lond) 352:173-188.

Cole AE, Nicoll RA (1984b) The pharmacology of cholinergic excitatory responses in hippocampal pyramidal cells. Brain Res 305:283290.

Connors BW (1984) Initiation of synchronized neuronal bursting in neocortex. Nature 310:685-687.

Connors BW, Gutnick MJ, Prince DA (1982) Electrophysiological properties of neocortical neurons in vitro. J Neurophysiol 48:13021320.

Cox CL, Metherate R, Weinberger NM, Ashe JH (1992) Synaptic potentials and amino acid antagonists in auditory cortex. Brain Res Bull 28:401-410.

Crick F, Koch C (1990) Some reflections on visual awareness. Cold Spring Harbor Symp Quant Biol 55:953-962.

Davies P, Maloney AJF (1976) Selective loss of central cholinergic neurons in Alzheimer's Disease. Lancet 2:1403.

Detari L, Vanderwolf CH (1987) Activity of identified cortically projecting and other basal forebrain neurones during large slow waves and cortical activation in anesthetized rats. Brain Res 437:1-8.

Eckhorn R, Bauer R, Jordan W, Brosch M, Kruse W, Munk M, Reitboeck HJ (1988) Coherent oscillations: a mechanism of feature linking in the visual cortex? Biol Cybern 60:121-130.

Engel AK, Kreiter AK, Konig P, Singer W (1991) Synchronization of oscillatory neuronal responses between striate and extrastriate visual cortical areas of the cat. Proc Natl Acad Sci USA 88:6048-6052.

Fox K, Armstrong-James M (1986) The role of the anterior intralaminar nuclei and $N$-methyl $\mathrm{D}$-aspartate receptors in the generation of spontaneous bursts in rat neocortical neurones. Exp Brain Res 63: 505-518.

Freeman WJ, Skarda CA (1985) Spatial EEG patterns, non-linear dynamics and perception: the neo-Sherrington view. Brain Res Rev 10:147-175.

Gray CM, Singer W (1989) Stimulus-specific neuronal oscillations in orientation columns of cat visual cortex. Proc Natl Acad Sci USA 86:1698-1702.

Hagan JJ, Morris RGM (1988) The cholinergic hypothesis of memory: a review of animal experiments. In: Psychopharmacology of the aging nervous system (Iversen LL, Iversen SD, Snyder SH, eds), pp 237323. New York: Plenum.

Halliwell JV, Adams PR (1982) Voltage-clamp analysis of muscarinic excitation in hippocampal neurons. Brain Res 250:71-92.

Hicks TP, Kaneko T, Metherate R, Oka J-I, Stark CA (1991) Amino acids as transmitters of synaptic excitation in nencortical sensory processes. Can J Physiol Pharmacol 69:1099-1114.

Jahnsen H, Llinas R (1984) Electrophysiological properties of guineapig thalamic neurones: an in vitro study. J Physiol (Lond) 349:205226.

Jasper HH, Carmichael L (1935) Electrical potentials from the intact human brain. Science 81:51-53.

Jasper HH, Tessier J (1971) Acetylcholine liberation from cerebral cortex during paradoxical (REM) sleep. Science 172:601-602.

Johnston MV, McKinney M, Coyle JT (1981) Neocortical cholinergic innervation: a description of extrinsic and intrinsic components in the rat. Exp Brain Res 43:159-172.

Kanai T, Szerb JC (1965) Mesencephalic reticular activating system and cortical acetylcholine output. Nature 205:80-82.

Kristt DA, McGowan RA, Martin-MacKinnon N, Solomon J (1985) Basal forebrain innervation of rodent neocortex: studies using ace- tylcholinesterase histochemistry, Golgi and lesion strategies. Brain Res 337:19-39.

Krnjevic K, Pumain R, Renaud I. (1971) The mechanism of excitation by acetylcholine in the cerebral cortex. J Physiol (Lond) 215:247268.

Kurosawa M, Sato A, Sato Y (1989) Stimulation of the nucleus basalis of Meynert increases acetylcholine release in the cerebral cortex in rats. Neurosci Lett 98:45-50.

Lamour Y, Dutar P, Rascol O, Jobert A (1986) Basal forebrain neurons projecting to the rat frontoparietal cortex: electrophysiological and pharmacological properties. Brain Res 362:122-131.

Leung L-WS, Yim C-YC (1991) Intrinsic membrane potential oscillations in hippocampal neurons in vitro. Brain Res 553:261-274.

Livingstone MS, Hubel DH (1981) Effects of sleep and arousal on the processing of visual information in the cat. Nature 291:554-561.

Llinas RR, Grace AA, Yarom Y (1991) In vitro neurons in mammalian cortical layer 4 exhibit intrinsic oscillatory activity in the 10- to 50$\mathrm{Hz}$ frequency range. Proc Natl Acad Sci USA 88:897-901.

Mason A, Larkman A (1990) Correlations between morphology and electrophysiology of pyramidal neurons in slices of rat visual cortex. II. Electrophysiology. J Neurosci 10:1415-1428.

McCormick DA (1989) Cholinergic and noradrenergic modulation of thalamocortical processing. Trends Neurosci 12:215-221.

McCormick DA, Prince DA (1986) Mechanism of action of acetylcholine in the guinea-pig cerebral cortex in vitro. J Physiol (Lond) 375:169-194.

McCormick DA, Connors BW, Lighthall JW, Prince DA (1985) Comparative electrophysiology of pyramidal and sparsely spiny stellate neurons of the neocortex. J Neurophysiol 54:782-806.

McKinney M, Coyle JT, Hedreen JC (1983) Topographic analysis of the innervation of the rat neocortex and hippocampus by the basal forebrain cholinergic system. J Comp Neurol 217:103-121.

Metherate R, Ashe JH (1991) Basal forebrain stimulation modifies auditory cortex responsiveness by an action at muscarinic receptors. Brain Res 559:163-167.

Misgeld U (1989) Muscarinic slow EPSPs in neostriatal and hippocampal neurons in vitro. Experientia [Suppl] 57:104-113.

Mody CK, McIntyre HB, Miller BL, Altman K, Read S (1991) Computerized EEG frequency analysis and topographic brain mapping in Alzheimer's disease. Ann NY Acad Sci 620:45-56.

Moriizumi T, Hattori T (1992) Separate neuronal populations of the rat globus pallidus projecting to the subthalamic nucleus, auditory cortex and pedunculopontine tegmental area. Neuroscience 46:701710 .

Moruzzi G, Magoun HW (1949) Brain stem reticular formation and activation of the EEG. Electroencephalogr Clin Neurophysiol 1:455473.

Nicoll RA (1988) The coupling of ncurotransmitter receptors to ion channels in the brain. Science 241:545-551.

Nicoll RA, Madison DV (1982) General anesthetics hyperpolarize neurons in the vertebrate central nervous system. Science 217:10551057.

Pantev C, Makeig S, Hoke M, Galambos R, Hampson S, Gallen C (1991) Human auditory evoked gamma-band magnetic fields. Proc Natl Acad Sci USA 88:8996-9000.

Paxinos G, Watson C (1986) The rat brain in stereotaxic coordinates. New York: Academic.

Perry EK, Tomlinson BE, Blessed G, Bergmann K, Gibson PH, Perry RH (1978) Correlation of cholinergic abnormalities with senile plaques and mental test scores in senile dementia. Br Med J 2:14571459.

Ribary U, Ioannides AA, Singh KD, Hasson R, Bolton JPR, Lado F, Mogilner A, Llinas R (1991) Magnetic field tomography of coherent thalamocortical $40-\mathrm{Hz}$ oscillations in humans. Proc Natl Acad Sci USA 88:11037-11041.

Richardson RT, DeLong MR (1990) Context-dependent responses of primate nucleus basalis neurons in a go/no-go task. J Neurosci 10: 2528-2540.

Rigdon GC, Pirch JH (1986) Nucleus basalis involvement in conditioned neuronal responses in the rat frontal cortex. J Neurosci 6:25352542.

Rye DB, Wainer BH, Mesulam MM, Mufson EJ, Saper CB (1984) Cortical projections arising from the basal forebrain: a study of cholinergic and noncholinergic components employing combined retro- 
grade tracing and immunohistochemical localization of choline acetyltransferase. Neuroscience 13:627-643.

Saper CB (1984) Organization of cerebral cortical afferent systems in the rat. II. Magnocellular basal nucleus. J Comp Neurol 222:313342.

Saper CB (1987) Diffuse cortical projection systems: anatomical organization and role in cortical function. In: Handbook of physiology (Mountcastle VB, ed), pp 169-210. Bethesda: American Physiological Society.

Shute CCD, Lewis PR (1967) The ascending cholinergic reticular system: neocortical, olfactory and subcortical projections. Brain 90:497520.

Silva LR, Amitai Y, Connors BW (1991) Intrinsic oscillations of neocortex generated by layer 5 pyramidal neurons. Science 251:432-435.

Sims NR, Bowen DM, Allen SJ, Smith CCT, Neary D, Thomas DJ, Davison AN (1983) Presynaptic cholinergic dysfunction in patients with dementia. J Neurochem 40:503-509.

Steriade M, Buzsaki G (1990) Parallel activation of thalamic and cortical neurons by brainstem and basal forebrain cholinergic systems. In: Brain cholinergic systems (Steriade M, Biesold D, eds), pp 3-62. Oxford: Oxford UP.

Steriade M, McCarley RW (1990) Brainstem control of wakefulness and sleep. New York: Plenum.

Steriade M, Gloor P, Llinas RR, Lopes da Silva FH, Mesulam M-M (1990) Basic mechanisms of cerebral rhythmic activities. Electroencephalogr Clin Neurophysiol 76:481-508.

Steriade M, Dossi RC, Pare D, Oakson G (1991) Fast oscillations (20$40 \mathrm{~Hz}$ ) in thalamocortical systems and their potentiation by meso- pontine cholinergic nuclei in the cat. Proc Natl Acad Sci USA 88: 4396-4400.

Stewart DJ, Macfabe DF, Vanderwolf CH (1984) Cholinergic activation of the electroencephalogram: role of the substantia innominata and effects of atropine and quinuclidinyl benzilate. Brain Res 322: 219-232.

Tsumoto T, Masui H, Sato H (1986) Excitatory amino acid transmitters in neuronal circuits of the cat visual cortex. J Neurophysiol 55:469-480.

Vanderwolf $\mathrm{CH}$ (1988) Cerebral activity and behavior: control by central cholinergic and serotonergic systems. Int Rev Neurobiol 30: 225-340.

Wainer BH, Mesulam M-M (1990) Ascending cholinergic pathways in the rat brain. In: Brain cholinergic systems (Steriade M, Biesold D, eds), pp 65-119. Oxford: Oxford UP.

Weinberger NM, Ashe JH, Metherate R, McKenna TM, Diamond DM, Bakin J (1990) Retuning auditory cortex by lcarning: a prcliminary model of receptive field plasticity. Concepts Neurosci 1:91-132.

Wenk H, Bigl V, Meyer U (1980) Cholinergic projections from magnocellular nuclei of the basal forebrain to cortical areas in rats. Brain Res Rev 2:295-316.

Whitehouse PJ, Price DL, Struble RG, Clark AW, Coyle JT, DeLong MR (1982) Alzheimer's disease and senile dementia: loss of neurons in the basal forebrain. Science 215:1237-1239.

Wilson FAW, Rolls ET (1990) Learning and memory is reflected in the responses of reinforcement-related neurons in the primate basal forebrain. J Neurosci 10:1254-1267. 